\title{
A Graduate Degree Program in Telecommunications Systems Engineering
}

\author{
J. J. Sluss, Jr., G. E. Crain, S. V. Kartalopoulos, H. H. Refai, and P. K. Verma \\ School of Electrical \& Computer Engineering \\ Telecommunications Systems Program \\ University of Oklahoma - Tulsa
}

\section{Introduction}

The education of students in the area of telecommunications systems engineering is of rising significance as global economies become ever more reliant upon telecommunications technologies and services. Notwithstanding its broad-based origins from within electrical engineering, the study of telecommunications systems is today recognized as an academic discipline in its own right. The University of Oklahoma (OU) - Tulsa is one of a select few that offers a Master of Science degree in Telecommunications Systems under the aegis of the School of Electrical and Computer Engineering. The degree has been designed with a common set of core courses: Telecommunications Industry Overview, Telecommunications Technology, Network Design and Management, Telecommunications Laboratory, and Professional Project. In addition, students may choose technical electives from among electrical and computer engineering, computer science, mathematics, and telecommunications systems courses. Students may also choose up to six credit hours of approved elective courses in relevant disciplines such as finance, telecommunications management, economics, and industrial engineering. A key resource supporting the program is the Telecommunications Interoperability Laboratory ${ }^{1}$, a facility designed to provide students with unmatched access to carrier-grade telecommunications technologies. Students entering the program are expected to have undergraduate preparation in electrical and computer engineering. This paper describes the curriculum and program goals, as well as the motivation behind their development.

\section{Motivation, Program Goals, and Organizational Structure}

Telecommunications is an important enabling technology which pervades all sectors of the global economy and the production of skilled technical professionals is necessary to provide for continuing advances in the development of new telecommunications products and services. Moreover, today's fastest growing technology businesses are heavily reliant upon the communication of information between computers. The principal goal of our program is to produce the most sought after engineering graduates; specifically, those who are prepared to work at the confluence of telecommunications, computing and business. The need for a program of this nature was recognized in the early 1990's by leaders of commerce in the Tulsa area. OU responded to that need in 1994 by proposing the Master of Science in Telecomputing degree renamed the Master of Science in Telecommunications Systems in the summer of 2002. The educational market for this program has already been demonstrated and we have produced our first graduates. This program has a traditional home department, the School of Electrical and 
Computer Engineering at the OU home campus in Norman. The program is principally offered by resident, full-time faculty in Tulsa at the OU-Tulsa Schusterman Center and extends OU's ability to meet its teaching, research and service missions. Distance learning technology has been extensively applied to exchange the course offerings between the Tulsa and Norman campuses. The addition of a course exchange program has enhanced both the initial offering of the Telecommunications Systems degree and those of the Norman campus Engineering and Business programs from which it is spawned. In addition, OU's research objectives are enhanced by the relationship between Tulsa and Norman faculty, in cooperation with industry and government partners.

\section{Curriculum}

The program requires all students to complete a minimum of 32 credit hours, including a professional project. All students are required to complete the following common core coursework:

\section{TCOM 5113 - Telecommunications Industry Overview -3 credit hours}

This course provides an overview of the telecommunications industry, with focus on the management of telecommunication and information technologies. The course provides an introduction to the strategic issues facing telecommunications managers in the competitive, global economy. The course explores telecommunications technology from the perspective of providers, users, and regulators. The history and current status of public and private networks (voice, data, video, wireless) are explored, as well as applications of these technologies and their implication for organizations. Regulation of and competition in the marketplace are also topics of examination.

\section{TCOM 5213 - Network Design and Management - 3 credit hours}

This course focuses on the fundamentals of systems analysis and design of voice and data communications networks. The course explores the technical, as well as managerial, aspects of developing an integrated communications network.

\section{TCOM 5272 - Telecommunications Laboratory - 3 credit hours}

This laboratory course reinforces the understanding of concepts and principles put forth in TCOM 5123 through a variety of "hands-on" networking exercises and experiments. The class emphasizes network performance, simulation, and the Internet protocols. The class is conducted in the Telecommunications Interoperability Laboratory ${ }^{1}$, a key resource supporting the teaching and research activities of the program.

\section{TCOM 5553 - Telecommunications Technology - 3 credit hours}

This course provides an overview of the technology utilized in telecommunications networks. The course spans the technology spectrum from embedded legacy systems to emerging technologies for transporting voice, data, 
and video traffic over long distances and throughout local areas. Specific topics include data networks, both local and metropolitan area; the telephone system (POTs, network synchronization and switching, ISDN, SONET, cellular telephone); video (NTSC, switching and timing, compressed video standards, such as MPEG and Px64 HDTV); and optical networking components and systems.

\section{TCOM 5671 - Professional Project Proposal - 1 credit hour}

One semester prior to the anticipated date of graduation, a student must enroll in this class. During enrollment, the student will propose a Professional Project that demonstrates a comprehensive grasp of his/her field of study. The student's Project Committee will review the proposal, approve its scope, and develop a plan for assessing the final project, including standards regarding performance and content.

\section{TCOM 5682 - Professional Project - 2 credit hours}

During the final semester of study, a student must enrolled in this class. The student must satisfactorily complete the Professional Project that was proposed and approved during enrollment in TCOM 5671. At the conclusion of the Project, the student's Project Committee will evaluate the written report of the Project and determine whether the Project has satisfactorily met the standards of the assessment plan established during the enrollment in TCOM 5671. In addition to the written report, the student will present an oral defense of the Professional Project which will be evaluated by the Project Committee. TCOM 5671 and TCOM 5672 cannot be taken during the same semester.

In addition to the common core coursework, students must complete at least 12 hours of technical elective coursework from Telecommunications Systems (TCOM), Electrical and Computer Engineering (ECE), Mathematics (MATH), and/or Computer Science (CS). A sample of available graduate-level technical electives from which students may choose include:

- Computer and Communications Security

- Fiber Optics

- Advanced Optical Networking

- Optical Information Processing

- Wireless Communications

- Wireless Networks and Standards

- Communication Theory

- Digital Systems Interfaces

- Multimedia Communications

- Stochastic Processes

- Partial Differential Equations 
At least one technical elective course from each of the following topical areas is strongly encouraged: optical networking and devices; wireless networking and devices; and network security. Constraints are flexible on the remaining 6 hours of elective coursework, allowing students to choose from business-related courses, such as telecommunications management, finance, economics, management of information systems, and industrial engineering.

\section{Admission}

Applicants to the program must submit official transcripts from an accredited Bachelors degreegranting institution, official scores from the Graduate Record Examination (GRE), a professional resume, and three letters of recommendation. All applicants must fulfill requirements for admission into the OU Tulsa Graduate College ${ }^{2}$. Students entering the program are expected to have undergraduate preparation in Electrical and Computer Engineering. For students with other undergraduate majors, full admission will require candidates to have taken, or to complete while a candidate with a minimum grade of B, four of the five following courses: Signals and Systems, Electromagnetic Fields, Electronics, Microprocessor System Design, and/or Upperdivision Electrical \& Computer Engineering Lab. In lieu of taking these leveling courses, students may opt to demonstrate their proficiency in these subject matters by taking the respective final examination and scoring a minimum grade of $\mathrm{B}$.

\section{Expected Outcomes}

We expect to produce engineering graduates that are highly sought after for their ability to work at the confluence of telecommunications, computing and business. Early graduation results point to initial success as all of our graduates, approximately 40, have found employment in telecommunications-related fields or have chosen to continue their graduate education by pursuing a doctoral degree. Another expected outcome of this program is that, by virtue of the research capability being established and intellectual property being created, OU-Tulsa will become a regional engine for economic development. We are presently in the process of instituting a comprehensive assessment strategy to monitor the effectiveness of our program in attaining stated goals.

\section{Conclusion}

This paper has presented a description of the Master of Science in Telecommunications Systems program at the University of Oklahoma - Tulsa. The program was created, under the aegis of the School of Electrical and Computer Engineering, to produce engineering graduates who are prepared to succeed in telecommunications-related fields. We conclude that our initial efforts have been successful in addressing the needs that spawned the creation of the program. 


\section{Bibliographic Information}

${ }^{1}$ J. J. Sluss, Jr., S. V. Kartalopoulos, H. H. Refai, M. J. Riley, and P. K. Verma, "The telecommunications interoperability laboratory," Proceedings of the American Society of Engineering Educators 2003 Annual Conference and Exposition, Nashville, TN, June 22-25, 2003.

${ }^{2} \mathrm{http}: / /$ tulsagrad.ou.edu/

\section{Biographical Information}

DR. JAMES SLUSS is a Professor of Computer Engineering in the Telecommunications Systems program at the University of Oklahoma, Tulsa. His research and teaching interests are in the areas of optical communications and photonics. He has been awarded seven U. S. patents and has authored/co-authored numerous journal and conference publications. He is a member of the IEEE Education Society, IEEE Communications Society, OSA, and ASEE.

DR. JERRY CRAIN has served as Director and Interim Director of Electrical and Computer Engineering since 1995. He came to OU as a Texas Instruments Professor in 1994 after 24 years in Advanced Radar at TI. His research interests are in Phased Array Radar, Antennas and Microwaves. BSEE Wichita University, MS/PhDEE University of Colorado.

DR. STAMATIOS KARTALOPOULOS is the Williams Professor in Telecommunications Networking, with interest in research and teaching Advanced Optical Networks at the TCOM graduate program of the University of Oklahoma, Tulsa. Previously, and for 22 years he was with Bell Labs. He is the author of seven books and of over 60 research papers. He also holds several patents. He is a member of IEEE, SPIE, Eta Kappa Nu, and Sigma Xi.

DR. HAZEM REFAI is an Assistant Professor of Computer Engineering in the Telecommunications Systems program at the University of Oklahoma, Tulsa. His research area is in modeling wireless communication systems: inter-vehicle communication, Wireless Local Area Networks (WLAN), and Cellular networks. He is a member of the IEEE Communications Society.

DR. PRAMODE VERMA is Director of the Telecommunications Systems program and Professor of Computer Engineering at the University of Oklahoma, Tulsa. He has held management positions with Lucent Technologies/Bell Laboratories for over twenty years. He is the author/coauthor of over 50 publications and several books in telecommunications and computer communication. 